\title{
Práticas Educativas: relato de experiência na unidade curricular de Engenharia de Software
}

\section{Educational Practices: report of experience in the curricular software engineering unit}

\author{
ANA SARA CASTAMAN \\ Instituto Federal de Educação, Ciência e Tecnologia do Rio Grande do Sul - Campus Sertão \\ LIS ÂNGELA DE BORTOLI
}

Instituto Federal de Educação, Ciência e Tecnologia do Rio Grande do Sul - Campus Sertão

\begin{abstract}
Resumo: O presente ensaio tem por finalidade apresentar um relato de experiência de práticas educativas implementadas na unidade curricular de Engenharia de Software, no Curso Superior de Tecnologia em Análise e Desenvolvimento de Sistemas (ADS), no Instituto Federal de Educação, Ciência e Tecnologia do Rio Grande do Sul (IFRS) - Campus Sertão. Para tanto, está pautado em uma metodologia de pesquisa de abordagem qualitativa empreendida em duas partes: a) apresenta o curso de ADS e a unidade curricular de Engenharia de Software, por meio do Projeto Pedagógico de Curso (PPC) e das diretrizes internacionais para a área de Engenharia de Software, b) analisa as estratégias de ensinagem desenvolvidas na unidade curricular de Engenharia de Software, compreendendo-as como práticas educativas. Conclui-se que as estratégias de ensinagem, enquanto práticas educativas, privilegiaram 0 desenvolvimento dos processos mentais, a formação de um sujeito autônomo e que partilha da construção do conhecimento.
\end{abstract}

Palavras-chave: Práticas educativas. Estratégias de ensino. Educação Profissional e Tecnológica. Engenharia de Software

\begin{abstract}
The purpose of this essay is to present an account of the experience of educational practices implemented in the Software Engineering course, in the Advanced Course in Technology in Analysis and Systems Development (ADS), at the Federal Institute of Education, Science and Technology of Rio Grande (IFRS) - Campus Sertão. For this, it is based on a research methodology of qualitative approach undertaken from two parts: a) presents the course of ADS and the curricular unit of Software Engineering, through the Pedagogical Course Project (PPC) and international guidelines for the area of Software Engineering, b) analyzes the teaching strategies developed in the course of Software Engineering, understanding them as educational practices. It is concluded that teaching strategies, as educational practices, have privileged the development of mental processes, the formation of an autonomous subject that shares the construction of knowledge.
\end{abstract}

Keywords: Educational practices. Teaching strategies. Professional and Technological Education. Software Engineering.

CASTAMAN, Ana Sara; DE BORTOLI, Lis Ângela. Práticas Educativas: relato de experiência na unidade curricular de 


\section{Introdução}

Os Institutos Federais de Educação, Ciência e Tecnologia (IF) fundamentam-se em princípios que anseiam por uma formação omnilateral do indivíduo e do coletivo (AGUIAR; PACHECO, 2017). Têm por objetivo assumir as exigências "[...] por formação profissional, por difusão de conhecimentos científicos e tecnológicos e de suporte aos arranjos produtivos locais" (BRASIL, 2010, p. 02), pautando-se em ações que se ocupam com a relação entre conhecimento e trabalho, por meio de uma compreensão de mundo na formação de seus sujeitos (RAMOS, 2014).

Logo, para dar conta deste princípio educativo, os IF necessitam difundir práticas educativas que permitam a mediação de conteúdos sedimentados à realidade do educando. Entende-se por práticas educativas aquelas que privilegiam a constituição do sujeito, mas não significa fazê-lo em detrimento da construção do conhecimento sobre o mundo. Assim, atrelam-se ambos os objetivos na proposta pedagógica da instituição educacional.

\footnotetext{
[...] o objeto da educação diz respeito, de um lado, à identificação dos elementos culturais que precisam ser assimilados pelos indivíduos da espécie humana para que eles se tornem humanos e, de outro lado e concomitantemente, à descoberta das formas mais adequadas para atingir esse objetivo (SAVIANI, 2008, p. 13).
}

Remete a reconhecer a identidade cultural dos mesmos, considerando a situação concreta, o meio existencial (FREIRE, 1996). Logo, o desafio da profissão docente é formar "[...] sujeitos pensantes, criativos, capazes de lidar com o novo, de transferir recursos conceituais e procedimentais, que lhes permitam criar soluções para os desafios que se manifestam" (CASTAMAN; VIEIRA, 2013, p. 08). Porém, grande parte do trabalho docente na Educação Profissional e Tecnológica (EPT) ainda reflete práticas de ensino tradicionais que não consideram as determinações sócio-históricas, inscritas no processo educacional.

Diante deste escopo e como servidoras no IF, atuando no curso Superior de Tecnologia em Análise e Desenvolvimento de Sistemas (ADS), problematiza-se: os professores que atuam na EPT, mais especificamente, no curso de ADS, inorporam/operam/desenvolvem práticas educativas que permitem a formação de um sujeito autônomo e que partilha da construção de seu conhecimento? Destarte, neste ensaio, tem-se por finalidade apresentar um relato de experiência das práticas educativas implantadas na unidade curricular de Engenharia de Software, no Curso Superior de ADS, no Instituto Federal de Educação, Ciência e Tecnologia do Rio Grande do Sul (IFRS) - Campus Sertão. A referida unidade curricular é ministrada no terceiro semestre e preocupa-se com a aplicação de teoria e prática para o desenvolvimento efetivo e eficiente de sistemas de software que satisfaçam os requisitos dos usuários, a partir de práticas educativas.

Para tanto, o presente artigo está pautado em uma metodologia de pesquisa de abordagem qualitativa empreendida em duas partes: a) apresenta o curso de ADS e a unidade curricular de Engenharia de Software, por meio do Projeto Pedagógico de Curso (PPC) e das diretrizes internacionais para a área de Engenharia de Software e b) analisa as estratégias de ensinagem 
desenvolvidas na unidade curricular de Engenharia de Software, compreendendo-as como práticas educativas.

\section{Curso de ADS e a Unidade Curricular de Engenharia de Software}

O Curso Superior de Tecnologia em Análise e Desenvolvimento de Sistemas (ADS), do IFRS, Campus Sertão, foi autorizado em 2013, está reconhecido pela Portaria no 1.038, de 23 de dezembro de 2015 e desenvolve-se no turno da manhã. Os estudantes são oriundos de várias cidades da região do Planalto Médio do Rio Grande do Sul e quatro turmas já o concluíram.

O curso foi concebido e estruturado para proporcionar aos discentes uma formação voltada ao desenvolvimento de sistemas de informação em instituições públicas e privadas, estudando a área de informática como atividade-meio. Atualmente, o curso possui trinta e sete componentes curriculares, distribuídos ao longo de seis semestres, totalizando uma carga horária de 2.230 horas. Tem por finalidade preparar profissionais para atuarem no mundo do trabalho, particularmente em uma área de forte impacto como a da Análise e Desenvolvimento de Sistemas, apresentando, assim, as características do meio em que esse profissional estará inserido (IFRS, 2014).

Ainda conforme informações coletadas no PPC (IFRS, 2014), por muito tempo, algumas instituições de ensino superior (IEs) têm criado um mundo virtual, para o qual a resolução de problemas independe ou precede estes. Porém, na realidade das organizações e, cada vez mais, no futuro, problemas e soluções devem ser negociados e entendidos de forma clara pelos envolvidos. Sendo assim, não é possível preparar estudantes para que dominem somente um método, metodologia ou ferramenta, mas, sim, contribuir para que se tornem aptos a resolver os infortúnios do mundo real. Não se pode formar profissionais preparados para integrarem-se em um mundo sem interagirem com ele, criando bolhas que os manteriam longe dos problemas e da dinâmica cada vez mais complexa e mutante do mundo e das organizações em que se atua.

Desta forma, o desafio está em preparar os estudantes para operarem em ambientes, nos quais as habilidades de relacionamento interpessoal, comunicação e de trabalho em grupo são as chaves para o bom exercício profissional. É preciso valorizar a relação entre reflexão, ação e, novamente, reflexão, destacando que os conhecimentos teóricos e conceituais são a base para a atuação na área, mas não suficientes para garantir o sucesso de suas ações no mundo profissional. Ressalta-se a necessidade de articular o campo intelectual ao trabalho produtivo, formando assim, trabalhadores capazes de atuar como dirigentes e cidadãos (GRAMSCI, 1991).

\footnotetext{
Nesse intuito, a Formação Cidadã precede a formação para o trabalho, buscando através da educação para a emancipação e autonomia a construção de sujeitos críticos, conhecedores de seu papel no mundo do trabalho e nas relações de produção, comprometidos com a superação das desigualdades historicamente estruturadas (IFRS, 2018, p. 05).
}

Pensando em dar conta de uma formação cidadã apontada no perfil do egresso (IFRS, 2014), na matriz curricular do curso de ADS, a área de engenharia de software é abordada por 
meio de seis componentes curriculares, assim nomeados: Engenharia de Software (60h), Análise e Projeto de Sistemas (60h), Interação Homem-Computador (30h), Teste e Qualidade de Software (60h), Gerência de Projetos (60h) e Laboratório de Sistemas de Informação (60h). Ainda, a unidade curricular de Ética e Legislação Aplicadas à Informática (60h) trata do conceito de ética na engenharia de software, a partir da proposta do Institute of Electrical and Electronic Engineers (IEEE) ${ }^{1}$ e da Association for Computing Machinery (ACM) ${ }^{2}$ (GOTTERBARN et al., 1999), demonstrando a interdisciplinaridade no curso.

No que tange a este estudo, toma-se como nicho a Unidade Curricular de Engenharia do Software, ministrada no terceiro semestre. Em seu ementário o foco está na mediação dos seguintes conteúdos: princípios fundamentais da Engenharia de Software; processo de software; modelos de processos de software; engenharia de requisitos; ferramentas CASE (IFRS, 2014).

A Engenharia de Software é uma área que se preocupa com a aplicação de teoria, conhecimento e prática para o desenvolvimento efetivo e eficiente de sistemas de software que satisfaçam os requisitos dos usuários (ACM/IEEE, 2014). Segundo as diretrizes da ACM/IEEE (2014) para cursos de Engenharia de Software, os estudantes precisam realizar tarefas que envolvam atuar como um indivíduo, mas também aquelas em que trabalham em grupo. Para o trabalho em grupo, os estudantes devem ser informados sobre a sua natureza, atividades e funções tão explicitamente quanto possível. Isto deve incluir uma ênfase na importância de questões como uma abordagem disciplinada, cumprimento de prazos, comunicação e avaliações de desempenho individual e de equipe.

Uma das diretrizes do referido documento aponta claramente que a educação em Engenharia de Software precisa ir além do formato tradicional de aula e considerar uma variedade de abordagens de ensino e aprendizagem (IFRS, 2014). Esta concepção está em consonância com a metodologia apresentada no PPC de ADS quando destaca a necessidade de constante relação entre teoria e prática, aulas expositivo-dialogadas, trabalho com diferentes tecnologias da área de informática, emprego de recursos audiovisuais, construção de referenciais teóricos e práticos por meio de coletânea de textos sobre temas abordados, participação em atividades de ensino, pesquisa e extensão, visando a integração das atividades curriculares previstas no curso e das atividades extracurriculares, participação em palestras, seminários e visitas técnicas (IFRS, 2014).

Diante do exposto, percebe-se que o Plano de Desenvolvimento Institucional (PDI), o PPC de ADS do IFRS - Campus Sertão e as diretrizes internacionais, definem uma visão de homem e de profissional que se pretende permitir na EPT; a função social da instituição escolar; os modos de ensinar e aprender; a organização curricular; os objetivos, os quais, em seu escopo, estão pautados em uma formação omnilateral. É neste contexto que, na seção que segue,

\footnotetext{
1 O Instituto de Engenheiros Eletricistas e Eletrônicos (IEEE) é uma organização profissional sem fins lucrativos, fundada nos Estados Unidos, em 1963 pela fusão do IRE e do AIEE. Atualmente, é a maior organização profissional do mundo em número de sócios. Seu objetivo é promover conhecimento no campo da engenharia elétrica, eletrônica e computação.

${ }^{2}$ A Association for Computing Machinery (ACM) é uma das maiores e mais reputadas associações científicas e educacionais dedicadas à computação. Foi fundada em 1974 e conta atualmente com mais de 100.000 associados em todo o mundo. A sua sede é em Nova Iorque, nos Estados Unidos da América.
} 
apresentam-se experiências desenvolvidas no componente curricular de Engenharia do Software no curso de ADS, do IFRS - Campus Sertão. Visa-se a retratar o trabalho docente, com a organização e operacionalização de estratégias ${ }^{3}$ de ensinagem ${ }^{4}$ (PIMENTA; ANASTASIOU, 2002) que se configuram como práticas educativas, no intuito da formação integral do sujeito.

\section{Práticas Educativas: uma experiência na Engenharia de Software}

Para dar conta das prerrogativas contidas no PDI, do perfil do estudante abarcado no PPC de ADS e das diretrizes internacionais para a área de Engenharia de Software, no plano de ensino, no descritor metodologia, a docente responsável apresenta que suas práticas educativas estarão sustentadas na concepção de aprendizagem sócio-histórica, num processo de interação, discussão e sistematização a partir de estudo teórico e prático. Assim, no plano de ensino está sendo prevista a possibilidade de realização de leituras, reflexões, painel integrado, aulas expositivo-dialogadas, mapas conceituais, seminários, sistematizações individuais e, no coletivo, o uso do laboratório de informática para a exploração de recursos dos softwares na prática, sendo um aluno por computador (DE BORTOLI, 2019).

Deste modo, na sequência, apresentam-se as estratégias de ensinagem empregadas na unidade curricular de Engenharia de Software, analisando-as enquanto práticas educativas. Foulin (2000) admite o conceito de estratégia de ensino, enquanto uma seleção entre vários procedimentos, a fim de alcançar um bom desempenho no processo de ensino e aprendizagem. Enfatiza-se que as estratégias de ensino distinguem-se em: cognitivas e metacognitivas.

As primeiras consideram os elementos da tarefa. Já as estratégias metacognitivas remetem às características do indivíduo. Dito de outro modo, o estudante emprega o conhecimento que há em seus processos mentais ${ }^{5}$, refletindo conscientemente acerca de seu pensar, da capacidade e funcionamento do mesmo. Este processo possibilita a autonomia e a construção do conhecimento (FOULIN, 2000).

Almeja-se em cada mediação de conteúdos estimular e/ou construir os processos mentais ou as operações do pensamento, tomando a síncrese inicial como ponto de partida e a síntese a ser construída como ponto de chegada, por meio da análise. Ainda, permite-se ao estudante sensações ou estados de espírito repletos de vivência pessoal e de renovação (ANASTASIOU; ALVES, 2015). Assim, passa-se ao relato do caso.

\footnotetext{
3 Adota-se neste ensaio o termo estratégias, enquanto a arte de aplicar ou explorar os meios e condições favoráveis e disponíveis, com a finalidade de efetivação da ensinagem. No entanto, matem-se a nomeclatura adotada por outros autores, quando tratam desse conceito.

4" [...] processo compartilhado de trabalhar os conhecimentos, no qual concorrem conteúdo, forma de ensinar e resultados mutuamente dependentes, é que estamos denominando de processo de ensinagem." (PIMENTA; ANASTASIOU, 2002, p. 214)

5 Raths, Rothsteins e Jonas (1977) remetem a alguns processos mentais: comparação, observação, imaginação, obtenção e organização dos dados, elaboração e confirmação de hipóteses, classificação, interpretação, crítica, busca de suposições, aplicação de fatos e princípios a novas situações, planejamento de projetos e pesquisas, análise e tomadas de decisão e construção de resumos.
} 


\title{
3.1 Onde você se encaixa?
}

Para Oliveira e Chadwick (2001), cada estudante desenvolve um modo próprio para aprender, sendo este chamado de estilo de aprendizagem. Logo, o docente ao identificar o estilo de aprendizagem, poderá planejar as situações de aprendizagem.

\begin{abstract}
O processo de ensino-aprendizagem é basicamente interativo e cabe ao educador fazer o papel de mediador entre o sujeito que aprende e o que se quer e busca aprender. Ter conhecimento das diferentes formas de aprender e respeitá-las é um aspecto que atinge diretamente a aprendizagem. O profissional que considera os estilos de aprendizagem de seus alunos tem condições de ajustar formas diferenciadas de como apresentar informações (BALECHE, 2015, p. 03).
\end{abstract}

Com base nesse aporte teórico, no primeiro dia de aula, para realizar um diagnóstico da turma e dos estilos de aprendizagem, realiza-se a dinâmica "Onde você se encaixa?", baseada no texto produzido pelo autor Celso Antunes, intitulado "Estilos de aprendizagem". O texto apresenta quatro estilos diferentes: poeta, soldado, estatístico e o compositor. Para tanto, distribuiu-se aos estudantes folhas contendo os referidos estilos com as devidas características, conforme quadro 1.

Quadro 1 - Estilos de Aprendizagem

\begin{tabular}{|c|c|}
\hline $\begin{array}{c}\text { Estilos de } \\
\text { Aprendizagem }\end{array}$ & Características \\
\hline Poeta & $\begin{array}{l}{[\ldots] \text { valoriza bem mais a jornada que o ponto de chegada, o encanto da procura que a sede de }} \\
\text { descoberta. }[\ldots] \text { fixa-se, }[\ldots] \text {, em analogias. }[\ldots] \text { mais o ajuda quem é capaz de bem compreendê-lo, } \\
\text { ajudando-o a ir do que Ihe parece "difícil" ou "complicado" ao que acha mais fácil, e de bem ensiná-lo a } \\
\text { construir significações a partir de exemplos concretos. }[\ldots] \text { o estilo de aprendizagem }[\ldots] \text { manifesta-se } \\
\text { com intensidade para questões que envolvem a pessoa e, }[\ldots] \text { Interessadíssimos nas relações } \\
\text { interpessoais, eles possuem valores éticos fortemente estabelecidos e, entre estes, a empatia ou a } \\
\text { "capacidade de sentir o outro em si mesmo"; }[\ldots] \text { aprendem com facilidade as disciplinas humanas, }[\ldots] \text {. } \\
\text { Alunos com essas características precisam de professores que lhes "acordem" a curiosidade, }[\ldots] \text { buscam } \\
\text { aqueles que oferecem desafios pela diversidade de linguagens. Produzem melhor se integrados em grupos } \\
{[\ldots] \text {. }}\end{array}$ \\
\hline Soldado & $\begin{array}{l}\text { Extremamente racionais e, geralmente organizados, usam sua capacidade de atenção de maneira } \\
\text { determinada e focada no alvo que desejam. Não se dispersam por quase nada, não vagueiam pela } \\
\text { criatividade e utilizam sempre, com extrema eficiência, o pensamento lógico-dedutivo; [...] Adeptos fiéis } \\
\text { da racionalidade }[\ldots] \text { necessitam de educadores objetivos que em tudo que lhes ensinar mostrem sempre } \\
\text { as relações de causa e efeito, os "porquês" das coisas, o "antes", o "agora" e o "depois" de cada tema, em } \\
\text { cada aula. Muito bons em comparar, analisar, sintetizar e classificar, necessitam de aulas em que essas } \\
\text { habilidades operatórias se apresentem claras e jamais se mostram atentos quando a objetividade que } \\
\text { sempre procuram se mostra perdida. [...] }\end{array}$ \\
\hline Estatístico & $\begin{array}{l}\text { [...] A atenção do estatístico é a objetividade dos fatos e a concretização das ações. Muito bons na } \\
\text { habilidade de descrever, são ainda melhores na capacidade de organizar e de sistematizar. Sua atenção e } \\
\text { seu interesse exigem reforços de diferentes linguagens; dessa forma, quando aprendem um texto, } \\
\text { transformando-o em gráfico ou figura, ou aprendem uma figura ou um gráfico, transformando em texto, } \\
\text { aprendem com mais segurança e guardam melhor na memória. Ávidos por experiências [...] uma prática } \\
\text { docente magnífica em todos os níveis de escolaridade é justamente propor a todos os estudantes esse } \\
\text { mágico exercício de perceber um tema e imaginá-lo expresso por diferentes linguagens. [...] } \\
\text { Extremamente pragmáticos, acreditam que toda ação corresponde a uma reação [...] }\end{array}$ \\
\hline
\end{tabular}



imagens, permitam livre associações. Estudantes observados de maneira rápida ou superficial parecem apresentar distúrbios do déficit atenção por buscar sempre se afastar do concreto e do racional à procura da transformação e da mudança. [...] são incapazes de ouvir alguma coisa sem aprendê-la associando a outras e imprimindo formas diferentes em concebê-la. [...] sua atenção se apoia na captação do todo por meio dos caminhos do imaginário.

Fonte: Antunes, 2018.

Após a leitura individual, cada um autoavalia e identifica os traços que melhor compõem seu comportamento. Destarte, diante dos dados coletados, a docente responsável pode estudar, escolher, organizar e propor as estratégias de ensinagem para que os estudantes apropriem-se do conhecimento, contemplando os inúmeros estilos de aprendizagem em sala de aula. Segundo Anastasiou e Alves (2015), o conhecimento do estudante pelo professor e seu crescente autoconhecimento são ações primordiais para a seleção e a operacionalização das estratégias de ensinagem, com seu modo de ser, de agir, de estar e de sua dinâmica pessoal.

\subsection{Maratona do Conhecimento}

A Maratona do Conhecimento ${ }^{6}$ em Engenharia de Software qualifica-se como um evento que ocorre durante todo o semestre letivo. Pelos procedimentos é semelhante a uma gincana, na qual os estudantes desenvolvem atividades práticas e de pesquisa, acerca das temáticas abordadas na unidade curricular. São participantes da Maratona todos os estudantes matriculados no componente curricular de Engenharia de Software no semestre vigente. Os conteúdos estudados podem ser visualizados no Quadro 2.

Quadro 2 - Conteúdos da Unidade Curricular de Engenharia de Software

\begin{tabular}{|c|l|}
\hline Item & \multicolumn{1}{|c|}{ Conteúdos } \\
\hline 1 & Software: Importância. Evolução. Características e componentes. Aplicações. Problemas e suas causas. Mitos. \\
\hline 2 & Engenharia de Software: Histórico. Objetivos. Definições. Problemas encontrados. \\
\hline 3 & Processos de desenvolvimento de software: Conceitos. Atividades. Modelos tradicionais. Modelos ágeis. \\
\hline 4 & Engenharia de requisitos: Conceitos. Problemas. Processo. \\
\hline 5 & Manutenção de software: Definição. Características. Problemas. Manutenibilidade. Tarefas. Efeitos colaterais. \\
\hline 6 & Ferramentas CASE: Conceitos. Benefícios. Problemas. \\
\hline
\end{tabular}

Fonte: Autoras, 2019.

\footnotetext{
${ }^{6}$ Esta é uma versão adaptada das análises empreendidas acerca da Maratona do Conhecimento, apresentada no artigo "Non-conventional dynamics in a Software Engineering Course: practical and ludic activities", escrito por De Bortoli (2018).
} 
A atividade tem características de gamificação, que nada mais é do que o uso de elementos de design de jogos em contextos não-jogo. Na gamificação há elementos de pontuação (pontos, níveis e conquistas), como nos videogames, no entanto aplicados no contexto educacional. Programas de gamificação podem ampliar a utilização de um serviço e alterar o comportamento, a fim de que os usuários trabalhem para alcançar esses objetivos e para atingir recompensas externas (NICHOLSON, 2017).

No início da Maratona a turma é dividida em equipes, de forma espontânea, e cada equipe deverá indicar um nome que a identifique e um coordenador. A equipe vencedora será a que conseguir o maior número de pontos (disponibilizados e controlados por planilha pelos participantes) e, no final do semestre, os pontos serão convertidos em uma nota, correspondente a um terço da média semestral. Por fim, os estudantes avaliam, individualmente, a Maratona, apontando potencialidades, limitações e indicando sugestões. Também realizam uma autoavaliação e avaliam seus colegas de grupo, atribuindo uma nota de 1 a 10. Os critérios considerados são: comprometimento, cooperação, organização, interesse e relacionamento com os colegas.

Apesar da Maratona do Conhecimento, enquanto ação macro, ser semelhante à gamificação e tipificada como uma abordagem comportamentalista, as tarefas empreendidas são independentes e possuem um princípio dialético (da síncrese à síntese). Logo, as estratégias escolhidas permitem que os estudantes efetivem inúmeras operações mentais, a partir do ponto de partida, que é a prática social dos mesmos.

Vasconcellos (1995) apresenta categorias que possibilitam conhecer a trajetória interrelacional da construção do conhecimento: a significação, a problematização, a criticidade, a práxis, a continuidade-ruptura, a historicidade e a totalidade. A elaboração da síntese do conhecimento será o momento final da metodologia dialética, já que haverá a consolidação de conceitos e sistematização dos conhecimentos, a partir da síntese individual ou em grupo da temática abordada.

Partindo da lógica dialética, a prática educativa deve ensinar a pensar, mais do que somente memorizar, ensinar a questionar o mundo mais do que aceitá-lo passivavemente, ensinar a criticar a Ciência mais do que recebê-la pronta (RONCA; TERZI, 1995, p. 51). Assim, as tarefas abordam perguntas e/ou desafios, relacionados aos assuntos do componente curricular e da prática social dos estudantes. Além disso, os alunos exercitam o trabalho em grupo, autonomia, responsabilidade, habilidades de comunicação nas formas oral e escrita, leitura e compreensão de textos em língua inglesa. Em qualquer aula do semestre pode ser proposta uma tarefa, sem prévio aviso. O quadro 3 apresenta exemplos de tarefas da Maratona, as quais tentam contemplar os estilos de aprendizagem verificados na atividade apresentada na seção 3.1 . 
Quadro 3 - Estratégias da Maratona em Engenharia de Software

\begin{tabular}{|c|c|c|c|}
\hline Tarefa & Pontos & Estratégia de Ensinagem & Operações Mentais \\
\hline 1 & 170 & $\begin{array}{l}\text { Tempestade cerebral + Expositivo-dialogada: O professor questiona o que } \\
\text { os estudantes conhecem acerca da temática para que expressem em palavras } \\
\text { ou frases curtas, evitando atitudes críticas. Em seguida, registra e organiza as } \\
\text { ideias apresentadas no quadro. Essa é uma forma de mobilizar as estruturas } \\
\text { mentais do estudante (busca conhecer a experiência vivencial). } \\
\text { De forma expositivo-dialogada, o professor contextualiza o tema, articulando o } \\
\text { conteúdo com a exposição apresentada pelos estudantes. Na sequência, } \\
\text { estabelece o diálogo abrindo o espaço para reflexão sobre o tema. } \\
\text { Por fim, para que os estudantes realizem a síntese integradora do diálogo, } \\
\text { apresentam-se as seguintes questões: } \\
\text { 1) Identificar outras } 4 \text { características importantes que um software deve } \\
\text { possuir. Explique cada uma e justifique. ( } 40 \text { pontos) } \\
\text { 2) Elaborar um conceito sobre Engenharia de Software. (30 pontos) } \\
\text { 3) Explicar o(s) porquê(s) desenvolver softwares é considerado um desafio. (30 } \\
\text { pontos) } \\
\text { 4) Explicar como o uso da internet mudou os sistemas de software. ( } 30 \text { pontos) } \\
\text { 5) Refletir acerca da diferença entre o desenvolvimento de um produto } \\
\text { genérico de software e o desenvolvimento de software sob demanda (ou sob } \\
\text { encomenda)? Considere características gerais, tempo, custo e adaptação do } \\
\text { software. ( } 40 \text { pontos) }\end{array}$ & $\begin{array}{l}\text { Imaginação } \\
\text { criatividade, busca de } \\
\text { suposições, } \\
\text { classificação. } \\
\\
\text { Obtenção } \\
\text { organização de dados, } \\
\text { interpretação, crítica, } \\
\text { decisão, comparação e } \\
\text { resumo. }\end{array}$ \\
\hline 2 & 100 & $\begin{array}{l}\text { Seminário: em um primeiro momento, o professor apresenta e justifica o tema } \\
\text { ou seleciona com o auxílio dos estudantes. Após, o docente desafia e orienta os } \\
\text { estudantes para que realizem pesquisas (bibliográficas, campo ou laboratório) e } \\
\text { registros acerca do tema. Organiza-se o calendário das apresentações. No caso } \\
\text { da Unidade Curricular em estudo, solicitou-se que pesquisassem sobre os } \\
\text { modelos de processo, considerando: as características, a representação gráfica, } \\
\text { os pontos fortes, as limitações e as aplicações. Por fim, o professor dirige a } \\
\text { sessão de crítica ao final de cada apresentação, fazendo comentários de cada } \\
\text { trabalho e exposição, organizando uma síntese integradora do que foi } \\
\text { apresentado. }\end{array}$ & $\begin{array}{l}\text { Análise, interpretação, } \\
\text { crítica, levantamento } \\
\text { de hipóteses, busca de } \\
\text { suposições, obtenção } \\
\text { de organização de } \\
\text { dados, comparação, } \\
\text { aplicação de fatos a } \\
\text { novas situações. }\end{array}$ \\
\hline
\end{tabular}




\begin{tabular}{|c|c|c|c|}
\hline 3 & 80 & 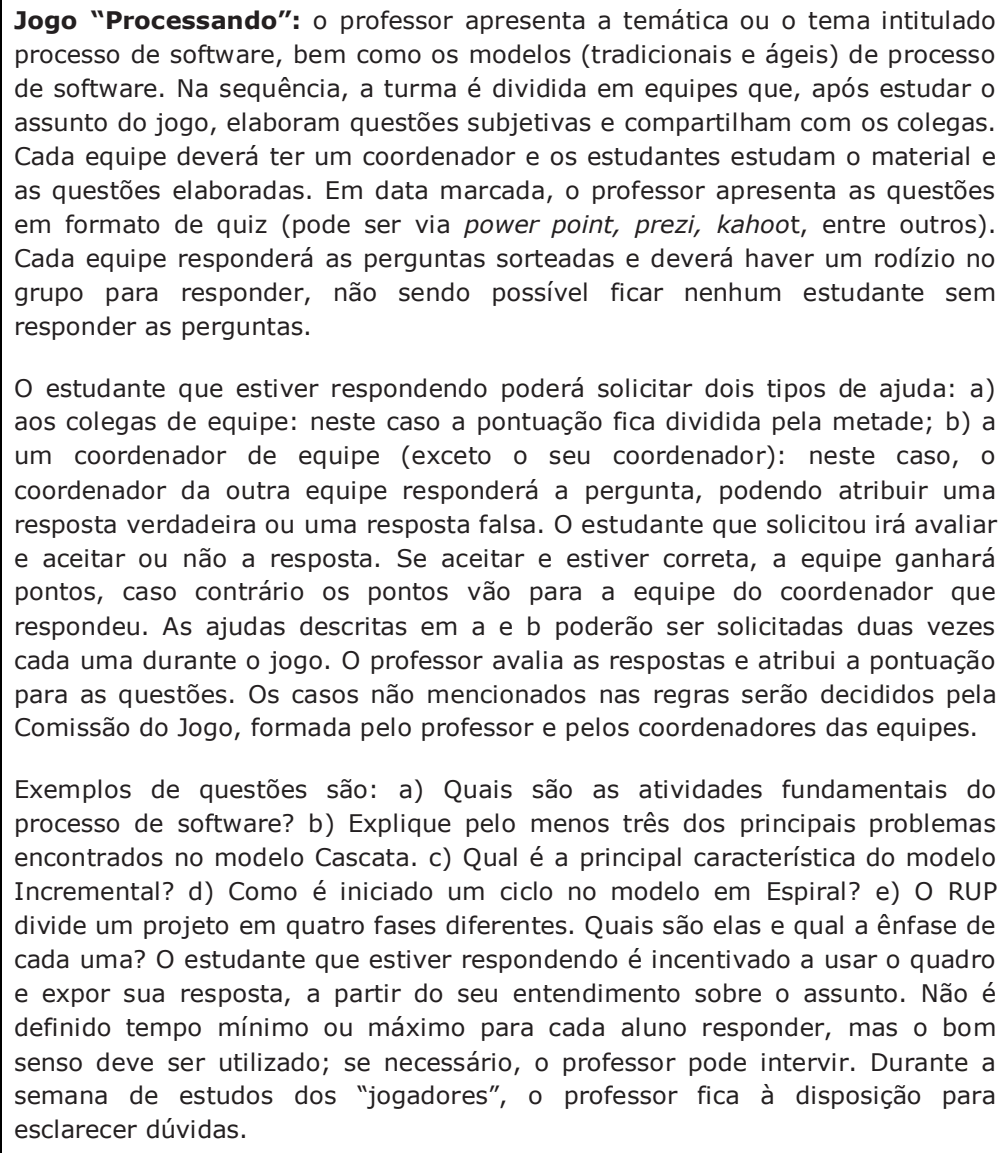 & $\begin{array}{l}\text { Identificação, obtenção } \\
\text { e organização de } \\
\text { dados, interpretação, } \\
\text { crítica, decisão, } \\
\text { análise, reelaboração, } \\
\text { resumo. }\end{array}$ \\
\hline 4 & 100 & $\begin{array}{l}\text { Estudo de texto: o professor apresenta um texto com data, tipo de texto, } \\
\text { autor e dados do autor. Na sequência, sugere-se ao estudante a análise } \\
\text { textual, visando ao esclarecimento quanto a gramática e temática. Após, } \\
\text { realiza-se um levantamento e discussão de problemas relacionados com a } \\
\text { mensagem do autor, problematizando-o. Por fim, o professor solicita aos } \\
\text { estudantes a síntese sobre os requisitos funcionais e não funcionais para um } \\
\text { sistema a ser definido. }\end{array}$ & $\begin{array}{l}\text { Identificação, obtenção } \\
\text { e organização de } \\
\text { dados, interpretação, } \\
\text { crítica, análise, } \\
\text { reelaboração, resumo. }\end{array}$ \\
\hline 5 & 200 & $\begin{array}{l}\text { Oficina: o professor organiza o grupo, o ambiente e o material didático } \\
\text { necessário à oficina. O grupo não deve ultrapassar a } 15 / 20 \text { pessoas. Pode ser } \\
\text { desenvolvida por meio das mais variadas atividades, como: os estudos } \\
\text { individuais, a consulta bibliográfica, as palestras, as discussões, a resolução de } \\
\text { problemas, as atividades práticas, a redação de trabalhos, as saídas a campo, } \\
\text { entre outras. Nesse caso, a proposta para a turma foi o desenvolvimento de } \\
\text { uma aplicação usando o processo ágil XP. }\end{array}$ & $\begin{array}{l}\text { Obtenção } \\
\text { organização de dados, } \\
\text { interpretação, } \\
\text { aplicação de fatos e } \\
\text { princípios a novas } \\
\text { situações, decisão, } \\
\text { planejamento de } \\
\text { projetos e pesquisas, } \\
\text { resumo. }\end{array}$ \\
\hline
\end{tabular}

Fonte: Autoras, 2019.

Em todas as aulas, um estudante é responsável pela 'memória de aula', ficando encarregado de registrar, em um documento compartilhado no Google Drive com toda a turma e com a professora, o que foi mediado naquele encontro (como compreendeu) e as tarefas recomendadas para a semana. Esta estratégia, que também é conhecida como Portfólio, tem 
por objetivo mobilizar as operações de pensamento de: identificação, obtenção e organização de dados, interpretação, crítica, análise, reelaboração e resumo. Por esse registro, que é analisado pela professora, o estudante recebe 20 pontos e, assim, todos podem ter acesso ao que foi trabalhado em aula, mesmo aqueles que não estiveram presentes.

Para o desenvolvimento de algumas atividades, os estudantes são incentivados a utilizar outros espaços disponíveis na instituição além do laboratório de informática, como salas de reuniões, salas de estudos em grupo da biblioteca e auditórios. Além disso, nas tarefas que envolvem trabalhos extraclasse, é necessário o uso de ferramentas de comunicação diferenciados como videoconferências, fórum e chats, uma vez que, conforme já mencionado, os estudantes residem em cidades geograficamente distantes do IFRS. Estas listas de discussões por meios informatizados promovem as operações mentais de comparação, observação, interpretação, busca de suposições, construção de hipóteses, obtenção e organização de dados.

Todas as tarefas são pensadas de modo que o estudante seja partícipe e construtor do conhecimento. Para Saviani (1995), a interação do professor e a participação ativa do aluno no processo ensino-aprendizagem são um meio de facilitar a aquisição de conhecimentos. A ideia é permitir que cada sujeito construa seu conhecimento e não simplesmente o repita. Nesta perspectiva, o estudante atua "[...] de forma significativa, responsável e com crescente autonomia, na busca da construção do conhecimento: supera-se o assistir pelo fazer aulas" (ANASTASIOU; ALVES, 2015, p.80).

\section{Considerações Finais}

Frente às considerações proferidas ao longo deste ensaio, chega-se a algumas constatações que, apesar de inconclusivas, conduzem a reflexões sobre a temática recortada. O objetivo deste artigo foi relatar experiências adotadas na unidade curricular de Engenharia de Software do curso de ADS do IFRS - Campus Sertão, utilizando práticas educativas que priorizam a formação omnilateral. Verificou-se que as estratégias de ensinagem apresentadas no plano de ensino como base metodológica e no relato de experiência estavam em consonância às prerrogativas apensadas no PDI, no PPC e nas diretrizes internacionais para a área de Engenharia de Software.

Foi possível constatar que as práticas educativas, a partir de uma metodologia dialética, pautada na abordagem sócio-cultural, compreendem que o trabalho pedagógico deve ser construído em parceria entre professor e estudante, ou seja, ensinando os educandos a refletir e a criticar, por meio de desafios ao funcionamento pleno e criativo de seu pensamento. Além disso, quando se elegem estratégias de ensinagem metacognitivas, tais como a Maratona do Conhecimento e o Jogo Processando, privilegiam-se o emprego e o desenvolvimento dos processos mentais, bem como a formação de um sujeito autônomo que partilha da construção do conhecimento. Este processo possibilita que o estudante compreenda o estudo e, por sua vez, os conteúdos como uma necessidade para a sua constituição autônoma, histórica e crítica. 
Embora todas as estratégias de ensino tenham potencialidades e fragilidades, o importante é que o professor busque variar para atender aos estilos de aprendizagem em sala de aula, considerando os objetivos e a finalidade de sua participação na formação dos sujeitos. Não obstante, este relato de experiência seja apenas o início de um processo de mobilização nos espaços da EPT, em especial, no curso de ADS do IFRS - Campus Sertão, acenam-se possibilidades de um trabalho pedagógico articulado a uma base conceitual atenta ao caráter teórico e prático, bem como contribuindo para uma Formação Cidadã e para o trabalho.

As considerações apresentadas neste ensaio são recentes e, portanto, necessitam ser aprofundadas e mais bem avaliadas em outros trabalhos de pesquisa. Contudo, entende-se que constituem apontamentos relevantes, pois parte-se de uma temática fecunda que permitirá outras investigações e análises de dados para pensar e contribuir sobre as práticas educativas. Pretende-se, ainda, explorar, em um próximo estudo, mais deste tema, de modo a mais bem compreender acerca das práticas educativas na EPT e verificar se há uma didática especial que orienta o trabalho pedagógico nesta modalidade.

\section{Referências}

AGUIAR, L. E. V. de; PACHECO E. M. Os Institutos Federais de Educação, Ciência e Tecnologia como política pública. In: ANJOS; M. B. dos; RÔSAS, G. As políticas públicas e o papel social dos Institutos Federais de Educação, Ciência e Tecnologia. Natal: IFRN, 2017.

ANASTASIOU, L. G. C.; ALVES, L. P. Processos de ensinagem na universidade. Pressupostos para as estratégias de trabalho em aula. 3. ed. Joinville: Univille, 2015.

ANTUNES, C. Estilos de Aprendizagem. São Paulo, 2018. Disponível em:

http://www.celsoantunes.com.br/estilos-de-aprendizagem-onde-voce-se-encaixa/. Acesso em: 27 mar. 2019.

BALECHE, F. L. K. Estilos de aprendizagem: um olhar para o aprendiz na prática pedagógica. In: Congresso Nacional de Educação (EDUCERE), XII, 2015, Curitiba/PR. Anais eletrônicos do Congresso Nacional de Educação (EDUCERE), XII. Curitiba/PR: Pontifícia Universidade Católica do Paraná, 2015. Disponível em: http://educere.bruc.com.br/arquivo/pdf2015/16034_8033.pdf. Acesso em: 27 mar. 2019.

BRASIL. Um novo modelo em educação profissional e tecnológica: concepção e diretrizes. Brasília,F: Secretaria de Educação Profissional e Tecnológica, 2010. Disponível em: http://portal.mec.gov.br/index.php?option=com_docman\&view=download\&alias=6691-ifconcepcaoediretrizes\&category_slug=setembro-2010-pdf\&Itemid=30192. Acesso em: 20 set. 2018.

CASTAMAN, A. S.; VIEIRA, M. M. M.. Formação continuada de professores da educação profissional. Regae: Rev. Gest. Aval. Educ. Santa Maria v. 2 n. 3 Jan./jun. 2013 p. 7-15.

DE BORTOLI, L. A. Non-conventional dynamics in a Software Engineering Course: practical and ludic activities. In: Simpósio Brasileiro de Engenharia de Software, 2018, São Carlos/SP. Anais eletrônicos do Simpósio Brasileiro de Engenharia de Software (SBES), XXXII. São Carlos/SP: Universidade Federal de São Carlos, 2018. Disponível em: https://doi.org/10.1145/3266237.3266257. Acesso em: 27 mar. 2019.

DE BORTOLI, L. A. Plano de Ensino da Unidade Curricular de Engenharia do Software. Instituto Federal de Educação, Ciência e Tecnologia do Rio Grande do Sul - Campus Sertão. 2019. Mimeo.

FOULIN, Jean-Noël. Psicologia da educação. 1. ed. Porto Alegre: Artes Médicas Sul, 2000.

FREIRE, P. Pedagogia da Autonomia. 35 ed., São Paulo: Paz e Terra, 1996. 
GOTTERBARN D. et al. How the new Software Engineering Code of Ethics Afeccts you, 1999. Disponível em https://pdfs.semanticscholar.org/a907/6d45189d8e7d86dde73c6c7e80519f8fc2ec.pdf. Acesso em: 16 out. 2018.

GRAMSCI, A. Os Intelectuais e a Organização da Cultura. Rio de Janeiro: Civilização Brasileira, 1991.

IFRS - Instituto Federal de Educação, Ciência e Tecnologia do Rio Grande do Sul - Campus Sertão. 2014. Projeto Pedagógico do Curso Superior de Tecnologia em Análise e Desenvolvimento de Sistemas. Disponível em http://www.sertao.ifrs.edu.br/site/midias/arquivos/20154713116670ppc_ads-2014.pdf. Acesso em: 20 fev. 2019.

IFRS - Instituto Federal de Educação, Ciência e Tecnologia do Rio Grande do Sul. Plano de Desenvolvimento Institucional 2019-2023. 2018. Disponível em: https://ifrs.edu.br/wp-content/uploads/2019/03/PDI-FINAL2018_Arial-1.pdf. Acesso em: 27 mar. 2019.

NICHOLSON, S.. A User-Centered Theoretical Framework for Meaningful Gamification. 2017. Disponível em pdf http://scottnicholson.com/pubs/meaningfulframework.pdf. Acesso em: 27 mar. 2019.

OLIVEIRA, J. B. A.; CHADWICK, C. Aprender e ensinar. 1. ed. São Paulo: Global, 2001.

PIMENTA, S. G.; ANASTASIOU, L. das G. C.. Docência no ensino superior. São Paulo: Cortez, 2002. (Coleção Docência em Formação).

RAMOS, M. N. Ensino Médio integrado: da conceituação à operacionalização. Cadernos de Pesquisa em Educação - PPGE/UFES, Vitória, EX, v. 19, n. 39, p. 15-29, jan/jun. 2014.

RATHS, L.; ROTHSTEINS, A. M.; JONAS, A. Ensinar a pensar: teoria e aplicação. São Paulo: EPU, 1977.

RONCA, P. A. C.; TERZI, C. do A. A Aula Operatória e a Construção do Conhecimento. São Paulo: Editora do Instituto Esplan, 1995.

SAVIANI, D. Escola e Democracia. São Paulo: Autores Associados, 1995.

SAVIANI, D. Pedagogia histórico-crítica: primeiras aproximações. Campinas: Autores Associados, 2008.

VASCONCELLOS, C. dos S. Metodologia dialética em sala de aula. AEC, v. 21, n. 83, abr./jun. 1995.

Recebido em abril de 2019.

Aprovado para publicação em fevereiro de 2020.

\section{Ana Sara Castaman}

Instituto Federal de Educação, Ciência e Tecnologia do Rio Grande do Sul - Campus Sertão - IFRS, Brasil, ana.castaman@sertao.ifrs.edu.br

\section{Lis Ângela De Bortoli}

Instituto Federal de Educação, Ciência e Tecnologia do Rio Grande do Sul - Campus Sertão - IFRS, Brasil, lis.debortoli@sertao.ifrs.edu.br 